\title{
Individual and Community-Level Factors of Perinatal Mortality in The High Mortality Regions of Ethiopia: A Multilevel Mixed-Effect Analysis
}

Desalegn Girma ( $\sim$ desegir@gmail.com )

Mizan Tepi University

Zinie Abita

Mizan Tepi University

Gossa Fetene

Mizan Tepi University

Bamlaku Birie

Mizan Tepi University

\section{Research Article}

Keywords: Ethiopia, perinatal mortality, regions, multilevel analysis.

Posted Date: August 18th, 2021

DOI: https://doi.org/10.21203/rs.3.rs-781800/v1

License: (1) This work is licensed under a Creative Commons Attribution 4.0 International License.

Read Full License

Version of Record: A version of this preprint was published at BMC Public Health on February 7th, 2022. See the published version at https://doi.org/10.1186/s12889-022-12695-y. 


\section{Abstract \\ Background}

Even though perinatal mortality has declined globally; it is still the major public health concern in subSaharan Africa countries. Ethiopia is one of the sub-Saharan countries which contribute the highestburden of perinatal mortality with devastating in some of the regions. Therefore, this study aimed to identify the determinant factors of perinatal mortality in the high mortality regions of Ethiopia.

\section{Method:}

A secondary data analysis was done by using the 2016 Ethiopian Demographic and Health Survey data. A total of 4120 mothers who had been delivered at $\geq 7$ months of gestational age were included. A multilevel mixed logistic regression model was fitted to identify the predictors of perinatal mortality. Finally, a statistically significant association was declared at a p-value of $\leq 0.05$.

\section{Result}

The study found that birth interval $<2$ years (AOR $=3.71,95 \% \mathrm{Cl}: 2.27,6.07)$, having no antenatal care (AOR $=2.43,95 \% \mathrm{Cl}: 1.15,5.38)$, Initiating breast feeding after 1 hour $(\mathrm{AOR}=4.01,95 \% \mathrm{Cl}: 2.49,6.51)$, being distant from health institutions $(A O R=1.99,95 \% \mathrm{Cl}: 1.24,3.22)$, having previous terminated pregnancy (AOR = $4.68,95 \% \mathrm{Cl}: 2.76,7.86)$, being mothers not autonomous( $\mathrm{AOR}=1.96,95 \% \mathrm{Cl}: 1.19,3.20)$,being no media exposure $(A O R=2.78,95 \% \mathrm{Cl}: 1.48,5.59)$, being households $\leq 4$ family sizes $(A O R=4.12,95 \% \mathrm{Cl}: 2.19,7.79)$, having $\geq 6$ parity $(A O R=2.48,95 \% \mathrm{Cl}: 1.21,5.22)$ were associated with a high odds of perinatal mortality.

\section{Conclusion}

The study concludes that birth interval, antenatal care, time for breastfeeding initiation, distance from health institutions, previous history of a terminated pregnancy, maternal autonomy, media exposure, family size, and parity were predictors of prenatal mortality. Therefore, programmatic emphases to maternal waiting service utilization for mothers distant from health institutions and increasing media access could reduce perinatal mortality in high mortality regions of Ethiopia.

\section{Background}

Perinatal mortality includes both terminated pregnancies after seven months (stillbirth) and early neonatal deaths in the first week of life ${ }^{13}$. It is an important indicator of the quality of maternal and neonatal care of the country ${ }^{18}$. 
Perinatal mortality is one of the public health concerns; globally, nearly 2 million annual stillbirths ${ }^{16}$ and about 2.4 million newborns death ${ }^{10}$ have been reported worldwide in 2019 , with the highest burden in low-income centuries. The risk of stillbirth is 7.6 times higher in low-income countries whereas the risk of newborn death is 9 times higher when compared to high-income countries ${ }^{15,16}$.

Even though there is a global decline in stillbirth from 2.9 million in 2000 to 2.0 million in $2019^{16}$ and neonatal deaths from 5.0 million in 1990 to 2.4 million in $2019^{10}$, perinatal mortality rate is still high in sub-sub-Saharan Africa countries which ranges from 34.7 to 42.95 per 1000 live births $^{2,29}$. It covers about 42 percent of the total still birth ${ }^{16}$ and 41 percent of the total newborn death ${ }^{15}$ of the globe.

The world has launched a platform "Every Newborn Action Plan (ENAP)" in 2014 to decline stillbirths and neonatal deaths to less than 10 per 1,000 total births of countries by $2035^{22}$. However, neonatal death and stillbirth have been reduced stagnantly in low-income countries and such countries need to accelerate the reductions of deaths to achieve the proposed targets ${ }^{33}$.

Ethiopia has also been working by endorsing "Every Newborn Action Plan" to reduce the rate of perinatal mortality, though it is still one of the major public health concerns, with a rate ranging from 33 to 51.3 deaths per 1000 births $^{8,17}$. The overall mortality rate has varation among regions and it was devastating in some of the regions in Ethiopia. According to 2016 Ethiopian Demographic and Health Survey (EDHS) report, perinatal mortality per 1000 live births was higher in Somali, Amhara, Harari, and Tigray regions( $50,44,40$ and 36 ,respectively $)^{8}$.

Perinatal mortality is occurred due to the interaction of factors such as paritry ${ }^{6,9,26}$, age of mother ${ }^{6,21}$, maternal education ${ }^{19,31}$, Attending ANC visits ${ }^{9}, 11,21,26$, skilled birth attendant ${ }^{9}$, previous history of perinatal mortality $9,14,21$, low family income, birth interval ${ }^{11,14,17}$, the total number of under 5 children $^{14}$, access to participation in decision making ${ }^{14}$, conceived during teenage ${ }^{27}$, and place of delivery 25,34 and residency ${ }^{26}$, and access to clean water supply ${ }^{13}$.

Even though Ethiopia has been working to decline perinatal mortality, by ensuring equity in health, maximizing the coverage, and improving the quality care of maternal and child health, perinatal mortality is still very high in some regions of Ethiopia (Somali, Amhara, Harari, and Tigray) ${ }^{24}$. Despite studies have been conducted on perinatal mortality in different part of Ethiopia, as per the knowledge of the investigeters, there is no study conducted on individual and community level factors in high perinatal mortality regions of Ethiopia as whole. Therefore, the primary aim of this study was to identify the individual and community level determinant factors of perinatal mortality in these high perinatal mortality regions of Ethiopia by using nationaly represetative data. Identtifing the individual and community level factors is significant to reduce perinatal mortality in high mortality regions of thiopia.

\section{Methods}




\section{Data source}

The 2016,Ethiopian Demographic and Health Survey (EDHS 2016) data were used, which was the fourth survey conducted nationally from January 18 to June 27, 2016. The respondents in EDHS,2016 were selected by using a two-stage stratified sampling technique. In the first stage, 645 enumeration areas (202 in urban areas and 443 in rural areas) were selected. Then in the second stage, 28 households per cluster have been selected. The detailed sampling technique was summarized in the full EDHS 2016 report ${ }^{8}$. For our study we have included at total of 4120 mothers who have delivered at $\geq 7$ months of gestational age from regions(Somali, Amhara, Harari, and Tigray) that have high rate of perinatal mortality based on 2016 EDHS report.

\section{Variables of the study}

\section{Dependent variable}

The perinatal mortality rate was a dependent variable, include both stillbirths and early neonatal deaths in the five years preceding the survey divided by all births (including stillbirths) that have a pregnancy duration of seven or more months. Stillbirth is defined as pregnancy terminated after seven or more months. Early neonatal death is death within seven days (days $0-6$ ). The out came variables was coded as " 0 " for the absence of perinatal mortality and " 1 " for the presence of perinatal mortality.

\section{Independent variables}

Predictors such as maternal age (years), maternal education status, paternal education status, Sex of household, working status of mothers, family size, wealth index, media exposure, age at first birth, place of delivery, preceding birth interval, women participating in making health care decisions, parity, time to breastfeeding Initiations, Postnatal care, previous history of a terminated pregnancy, antenatal visit, TT vaccination, and Health insurance were considered as individual-level factors. And factors such as residence, distance from health facilities, water facility, and times to reach the water source were considered as community-level factors.

\section{Statical analysis.}

Data were extracted by using SPSS version 21 software and then exported to R version 3.5.3 statistical software for further analysis. Data editing, coding, and cleaning were done. Frequencies, percentages, and the rate were used to summarize data, and tables were used to present data. Since the data in EDHS was collected by using multi-stage stratified cluster sampling techniques; a hierarchical nature of the data was considered. So multilevel mixed logistic regression model was fitted. Both bivariable and multivariable analyses were conducted. Variables that have a P-value of $\leq 0.25$ in bivariable two-level binary logistic regression were candidate for multivariable multilevel logistic regression analaysis. Then Variables in multilevel multivariable logistic regression were declared to be statistically significant at a Pvalue of $\leq 0.05$. 
Four models have been developed, With an assumption of varying intercepts across communities (clusters) but fixed coefficients. The first was the null model (Model I) fitted without predictors variables. The second model (model II) was fitted for individual-level factors and conducted to examine the contribution to the variation of perinatal mortality. Whereas the third model (Model III) was adjusted for community-level factors and used to examine the contribution for variation of perinatal mortality across the cluster. The model goodness of fit was tested using deviance information criteria (DIC)and the model with the lowest value was considered to be the best fit model.

To measures, the random effect, the intraclass correlation coefficient (ICC), median odds ratio (MOR), and proportional change in variance (PCV) statistics were computed. The ICC measures the variation withincluster. The PCV measures the total variation at individual and/or community-level factors of each model. The MOR measures the median odds ratio of perinatal mortality at the high-risk cluster and lower risk cluster when we select randomly two pregnancies from two clusters. The formulas for these 3 measurements are as follows:

ICC $=\mathrm{v}_{\mathrm{i}} /\left(\mathrm{v}_{\mathrm{i}}+\pi^{2} / 3\right) \sim \frac{V i}{V i+3.29}$,
$\mathrm{PCV}=\frac{V i-V y}{V i}$, where $\mathrm{v}_{\mathrm{i}}$, the variance of in each model
Where $\mathrm{v}_{\mathrm{i}}$ variances of the null model, $\mathrm{v}_{\mathrm{y}}$, variance of the model with more terms. $\mathrm{MOR}=\exp \cdot[\sqrt{2 \times} \mathrm{Vz} \times 0.6745] . \exp \cdot[0.95 \sqrt{V z}]_{\text {where, } \mathrm{v}_{\mathrm{z}^{*}} \text {, is variance at the }}$ cluster level.

\section{Results}

\section{Perinatal mortality by socio-demographic characteristics}

Out of the total 4120 study participants, about 3360(81.6\%) were rural residents and $2892(70.2 \%)$ of study participants didn't have formal education. The overall perinatal mortality rate in high mortality regions of Ethiopia was 47 per 1000 births. The perinatal mortality rate was high among mothers $\geq 35$ years (58.59 per 1000), households $\leq 4$ family size (68.64 per 1000), households who had Poor wealth index (61.40 per 1000 and mothers who didn't have media exposure (63.05 per 1000) (Table 1).

\section{Perinatal mortality by reproductive health characteristics}

Out of the total 4120 respondents, about 2002(48.6\%) mothers had first birth at age less than 18 years, and $2267(55.0 \%)$ had been delivered at home. Perinatal mortality was highest among mothers who have previous history of terminated pregnancy (120.72 per 1000), mothers who had home delivery (61.02 per 1000), mothers who didn't have participation in making health care decisions (91.11 per 1000), mothers who have a birth interval of $<2$ years ( 88.86 per 1000$)$, mothers who had $\geq 6$ parity ( 63.25 per 1000 ), 
mothers who didn't have ANC follow up (79.11 per 1000), and among mothers who had a big problem of distance from the health facility (85.90 per 1000) (Table 2).

\section{Random Effect And Model Comparison}

The fourth model was the best-fitted model. Hince, it had the lowest deviance value(566.6). The ICC for the null model was $(0.1)$; which indicates that $10 \%$ of the variability of perinatal mortality was due to differences between clusters. The value of MOR (1.77) in the null model indicates that there was a variation of perinatal mortality between clusters, if we randomly select a pregnant mother from two different clusters, the odd of perinatal mortality in the high-risk cluster was 1.77 times higher when compared to pregnant mother from the lowest risk cluster. The PCV in the fourth model was (0.27), which means that $27 \%$ of the variability of perinatal mortality was explained by both the individual level and community-level factors (Table 3 ).

\section{Factors associated with perinatal mortality.}

The fourth model was used to determine the associated factors with perinatal mortality. Based on this, the odds of perinatal mortality were 3.71 times higher (AOR $=3.71,95 \% \mathrm{Cl}: 2.27,6.07)$ among mothers who have $<2$ years' birth interval. The odd of perinatal mortality was 2.43 times higher $(A O R=2.43$, $95 \% \mathrm{Cl}: 1.15,5.38)$ among mothers who didn't have antenatal ANC visits as compared to mothers who have $\geq 4$ visits. The odd of perinatal mortality were 4.01 times higher ( $\mathrm{AOR}=4.01,95 \% \mathrm{Cl}: 2.49,6.51)$ among mothers who didn't start breastfeeding within one hour of birth as compared to mothers who startes with one hours. The odd of perinatal mortality were nearly two times higher ( $\mathrm{AOR}=1.99,95 \% \mathrm{Cl}$ : $1.24,3.22)$ among mothers who were far from health institutions as compared to their counterparts. The odd of perinatal mortality were 4.68 times higher ( $\mathrm{AOR}=4.68,95 \% \mathrm{Cl}: 2.76,7.86)$ among mothers who have previous history of terminated pregnancy as compared to mothers who didn't have previous history of terminated pregnancy. The odd of perinatal mortality were nearly two times higher (AOR $=1.96$, $95 \% \mathrm{Cl}: 1.19,3.20)$ among mothers who didn't have autonomy in making health care decisions as compared to their counterparts. The odds of perinatal mortality among mothers who didn't have media expossure was 2.78 times higher $(\mathrm{AOR}=2.78,95 \% \mathrm{Cl}: 1.48,5.59)$ as compared to mothers who have media exposure. Being Households $\leq 4$ family sizes were associated with a higher odds of perinatal mortality $(A O R=4.12,95 \% \mathrm{Cl}: 2.19,7.79)$ as compared to households with greater than four family sizes. The odds of perinatal mortality among mothers who have $\geq 6$ parity were 2.48 times higher $(A O R=2.48$, $95 \% \mathrm{Cl}: 1.21,5.22)$ as compared to mothers who have one to three parity(Table 4).

\section{Discussion}

The study aimed to identify the individual and community-level factors of perinatal mortality in high mortality regions of Ethiopia. Our study found that birth interval, media exposure, ANC follow up, time to breastfeeding initiation, maternal parity, previous history of terminated pregnancy, family size, women 
participation health care decisions and distance from a health facility were significant predictors of perinatal mortality.

The study revealed that mothers who gave birth in less than 2-year intervals have higher odds of perinatal mortality as compared to those who gave birth after 2-year intervals. The finding is supported by other studies $^{3,4}, 11,12,14,17$. The possible explanation may be due to that short birth intervals hurt the nutritional recovery, healing of the endometrium, cervical competency, and the optimal lactation of the breast which determines the outcomes of the succeeding pregnancy ${ }^{7}$. Thus, measures should be taken to promote family planning utilization to space the succeeding pregnancy.

The odds of perinatal mortality were higher among mothers who didn't have antenatal care visit as compared to mothers who have four and above antenatal care visits. The finding is supported by other studies $9,11,21,26,29$. The possible justification might be due to that having more antenatal care visits was an opportunity for health professionals for giving health education, identifying pregnancy with complications, and for treating an existing disease ${ }^{32}$. In addition, having a quality antenatal care service will facilitate mothers to deliver in a health institution , and increased the knowledge of mothers regarding the care that has been given in health institutions such as essential newborn care ${ }^{28}$.

The study revealed that mothers who have no autonomy in making health care decisions are more likely to have higher odds of perinatal mortality as compared to their counterparts. This is in agreement with the study conducted in Bangladesh ${ }^{14}$. The possible explanation may be due to those women who are autonomous in making health care decisions were more likely to have antenatal follow up ${ }^{1,20,30}$, postnatal cares ${ }^{20,30}$, and delivered at health facility ${ }^{1,30}$. It is crucial to identify and treat an existing complication in pregnancy and early in the newborn baby.

Unlike the study done in Bangladesh ${ }^{14}$, in this study, mothers who have no media exposure have higher odds of perinatal mortality as compared to their counterparts. Here, the possible justifications for such finding may be due to the fact that those mothers who have media exposure are more likely to use maternal and child health services, such as antenatal care, postnatal care, and institutional delivery ${ }^{1,20}$. Having this care will be a good opportunity for health professionals to provide health education for mothers regarding their pregnancy, newborn and to treat existing health problems ${ }^{28,32}$. The implication here is, health extension professionals should strengthen their role on health education and should reach the distal community.

In agreement with studies ${ }^{4,9}$, this study found that mothers who have previous history of terminated pregnancy have higher odds of perinatal mortality compared to their counterparts. This might be due that the genetic make-up of mothers and repeated exposure to environmental factors or this might be due to the problems related to the reproductive organs such as the uterus, and cervix or it may be due to problems related to the anatomical structure of the pelvic floor. In addition to this, it can be explained as the cultural impact in the community may force the couples to replace the lost fetus or newborn within a short birth interval without full recovery of mothers; this will determine the outcomes of pregnancy. Thus, 
mothers should be linked to reproductive health services and counseled on birth intervals. In addition, special investigation and care should be considered in the next pregnancy.

Late initiate of breastfeeding (after one hour) is the other factor that show high odds of perinatal mortality (early newborn). The finding is supported by the study conducted in India ${ }^{23}$. The possible reason might be due to that timely initiation of breastfeeding is an assurance that a newborn has received colostrum; which contains infection protecting antibodies and therefore, it will reduce early newborn mortality resulted from infectious diseases. Thus, measures such as health education in every birth are needed to initiate breastfeeding within one hour of birth.

Unlink to the other study ${ }^{5}$, this study found that being far from the health institutions is significantly associated with higher odds of perinatal mortality. The fact that proximity to a health institution will reduce the burden of transportation and helps the mother to have antenatal care and institutional delivery, which was an important opportunity to screen and to treat an existing disease in early newborn and pregnant mothers. This has a programmatic implication that the maternal waiting service should be strengthened and special consideration should be given to pregnant mothers thus far from health institutions.

Being household $\leq 4$ family sizes were associated with a higher odds of perinatal mortality as compared to households who had greater than four family sizes. The finding is supported by a study in West Gojam $z^{3} e^{34}$. The possible explanation might be due to the fact that large family members will reduce the workload of pregnant mothers in homes and will give enough time for resting and attending hospital follow-up care such as antenatal and postnatal care. Such care will have an advantage on the outcomes of the pregnancy.

The odd of perinatal mortality is higher among mother who have six parity compared to mother have one to three parity. The finding is in agreement with the study conducted in Sekota ${ }^{26}$ and contrary to the study has done in Jimma ${ }^{9}$. This can be explained as the mother who have high parity may deliver by short birth interval or it might be due to the age of mothers, that aged mother most of the time have high parity and such age will predispose mothers to obstetrics related factors that will contribute for perinatal mortality. Thus, grand Para mothers should be seen in special during antenatal care and delivery.

\section{Strength And Limitation}

The study has used nationality representative data of 2016 EDHS with a large sample size and highquality data which will reduce a bias related to sampling and measurement. Besides, we have employed an appropriate statistical approach (multilevel mixed analysis) to estimate the cluster effect on perinatal mortality. However, the study shares the limitation of a cross-sectional study that was impossible to establish the cause and effect relationship.

\section{Conclusion}


The study concludes that birth interval, antenatal care, time to breastfeeding initiation, distance from health institutions and previous history of a terminated pregnancy, maternal autonomy, media exposure, family size, and parity were predictors of prenatal mortality. Therefore, programmatic emphases to maternal waiting service utilization for mothers distant from health institutions and increasing media access could reduce perinatal mortality in high mortality regions of Ethiopia. In addition, strengthening maternal and child health services utilization and empowering mothers in making health care decisions should be emphasized.

\section{Abbreviations}

AIC

Akaike's information criterion; ANC:Antenatal care; AOR:Adjusted odds ratio; Cl:Confidence intervals; CSA:Central Statistical Agency; DIC:Deviance information criterion; EAs:Enumeration areas; EDHS:Ethiopian Demographic and Health Survey; ICC:intraclass correlation coefficient; MOR:Median odds ratio; PCV:Proportional change in variance; TT:Tetanus toxoid and ENAP:Every Newborn Action Plan

\section{Declarations}

\section{Ethics approval and consent to participate}

Since we have used a secondary data analysis that was publically available from the MEASURE DHS program, ethical approval and participant consent were not necessary. We had requested DHS Program and permission was allowed to download to use the data from https://www.dhsprogram.com/ there are no names of household addresses or individuals in the data.

\section{Consent for publication}

Not applicable

\section{Availability of data and materials}

The data is available and may be provided upon request

\section{Competing interests}

The authors declare that they have no competing interests.

\section{Funding}

The authors did not receive funding for this study

\section{Authors' contributions}


DG and ZA drafted the proposal, did the analysis, wrote the results, and organized the manuscript.BB Contributed on editing, analysis, and write up of the result, and GF critically revised the manuscript for its scientific content. All authors read and approved the final manuscript.

\section{Acknowledgments}

We would like to thank the measure DHS program for providing the data set.

\section{References}

1. Sohail Agha, and Thomas W Carton, 'Determinants of Institutional Delivery in Rural Jhang, Pakistan', International journal for equity in health, 10 (2011), 1-12.

2. Blessing Jaka Akombi, and Andre Masumbuko Renzaho, 'Perinatal Mortality in Sub-Saharan Africa: A Meta-Analysis of Demographic and Health Surveys', Annals of global health, 85 (2019).

3. Gulam Muhammed Al Kibria, Vanessa Burrowes, Allysha Choudhury, Atia Sharmeen, Swagata Ghosh, Arif Mahmud, and KC Angela, 'Determinants of Early Neonatal Mortality in Afghanistan: An Analysis of the Demographic and Health Survey 2015', Globalization and health, 14 (2018), 1-12.

4. Gashaw Andargie, Yemane Berhane, Alemayehu Worku, and Yigzaw Kebede, 'Predictors of Perinatal Mortality in Rural Population of Northwest Ethiopia: A Prospective Longitudinal Study', BMC public health, 13 (2013), 1-7.

5. Getayeneh Antehunegn, and Misganaw Gebrie Worku, 'Individual-and Community-Level Determinants of Neonatal Mortality in the Emerging Regions of Ethiopia: A Multilevel Mixed-Effect Analysis', $B M C$ pregnancy and childbirth, 21 (2021), 1-11.

6. Anna Agnes Ojok Arach, James K Tumwine, Noeline Nakasujja, Grace Ndeezi, Juliet Kiguli, David Mukunya, Beatrice Odongkara, Vincentina Achora, Justin B Tongun, and Milton W Musaba, 'Perinatal Death in Northern Uganda: Incidence and Risk Factors in a Community-Based Prospective Cohort Study', Global Health Action, 14 (2021), 1859823.

7. Agustín Conde-Agudelo, Anyeli Rosas-Bermudez, Fabio Castaño, and Maureen H Norton, 'Effects of Birth Spacing on Maternal, Perinatal, Infant, and Child Health: A Systematic Review of Causal Mechanisms', Studies in family planning, 43 (2012), 93-114.

8. I Csa, 'Central Statistical Agency (Csa)[Ethiopia] and Icf. Ethiopia Demographic and Health Survey, Addis Ababa', (2016).

9. Gurmesa Tura Debelew, 'Magnitude and Determinants of Perinatal Mortality in Southwest Ethiopia', Journal of Pregnancy, 2020 (2020).

10. United Nations Inter-agency Group for Child Mortality Estimation, 'Levels \& Trends in Child Mortality: Report 2020, Estimates Developed by the Un Inter-Agency Group for Child Mortality Estimation', (2020).

11. Abdi Geda, Shuayib Shemsu, and Rukiya Debalke, 'Determinants of Perinatal Mortality in Public Hospitals of Iluu Abbaa Boor Oromia Region, South West Ethiopia, 2019: Unmatched Case-Control 
Study', Research and Reports in Neonatology, 11 (2021), 57-66.

12. Yemisrach Getiye, and Mesganaw Fantahun, 'Factors Associated with Perinatal Mortality among Public Health Deliveries in Addis Ababa, Ethiopia, an Unmatched Case Control Study', BMC pregnancy and childbirth, 17 (2017), 1-7.

13. Y Guevvera, 'World Health Organisation: Neonatal and Perinatal Mortality: Country, Regional and Global Estimates', WHO cebu: sun (2006).

14. Md Belal Hossain, Sabuj Kanti Mistry, Md Mohsin, and Md Hasinur Rahaman Khan, 'Trends and Determinants of Perinatal Mortality in Bangladesh', PloS one, 14 (2019), e0221503.

15. Lucia Hug, Monica Alexander, Danzhen You, Leontine Alkema, and UN Inter-agency Group for Child, 'National, Regional, and Global Levels and Trends in Neonatal Mortality between 1990 and 2017, with Scenario-Based Projections to 2030: A Systematic Analysis', The Lancet Global Health, 7 (2019), e710-e20.

16. Lucia Hug, Anu Mishra, Sinae Lee, Danzhen You, Allisyn Moran, Kathleen Louise Strong, and Bochen Cao, 'A Neglected Tragedy the Global Burden of Stillbirths: Report of the Un Inter-Agency Group for Child Mortality Estimation, 2020', (United Nations Children's Fund, 2020).

17. Belayneh Hamdela Jena, Gashaw Andargie Biks, Kassahun Alemu Gelaye, and Yigzaw Kebede Gete, 'Magnitude and Trend of Perinatal Mortality and Its Relationship with Inter-Pregnancy Interval in Ethiopia: A Systematic Review and Meta-Analysis', BMC pregnancy and childbirth, 20 (2020), 1-13.

18. Barbara Madaj, Helen Smith, Matthews Mathai, Nathalie Roos, and Nynke van den Broek, 'Developing Global Indicators for Quality of Maternal and Newborn Care', (2017).

19. Eunice Francisca Martins, Edna Maria Rezende, Maria Cristina de Mattos Almeida, and Francisco Carlos Félix Lana, 'Perinatal Mortality and Socio-Spatial Inequalities', Revista latino-americana de enfermagem, 21 (2013), 1062-70.

20. Dinabandhu Mondal, Suranjana Karmakar, and Anuradha Banerjee, 'Women's Autonomy and Utilization of Maternal Healthcare in India: Evidence from a Recent National Survey', PLoS One, 15 (2020), e0243553.

21. Ugochukwu Uzoechina Nwokoro, Tukur Dahiru, Abdulhakeem Olorukooba, Clement Koelengoen Daam, Hyelshini Samuel Waziri, Ayo Adebowale, Ndadilnasiya Endie Waziri, and Patrick Nguku, 'Determinants of Perinatal Mortality in Public Secondary Health Facilities, Abuja Municipal Area Council, Federal Capital Territory, Abuja, Nigeria', The Pan African Medical Journal, 37 (2020).

22. World Health Organization, 'Every Newborn: An Action Plan to End Preventable Deaths', (2014).

23. Deepika Phukan, Mukesh Ranjan, and LK Dwivedi, 'Impact of Timing of Breastfeeding Initiation on Neonatal Mortality in India', International breastfeeding journal, 13 (2018), 1-10.

24. J Requejo, J Bryce, C Victora, A Deixel, A Barros, and Z Bhutta, 'Fulfilling the Health Agenda for Women and Children: The 2014 Report', Geneva: United Nations Children's Fund and World Health Organization (2014).

25. Elias Merdassa Roro, Mitike Molla Sisay, and Lynn M Sibley, 'Determinants of Perinatal Mortality among Cohorts of Pregnant Women in Three Districts of North Showa Zone, Oromia Region, 
Ethiopia: Community Based Nested Case Control Study', BMC public health, 18 (2018), 1-11.

26. Eshetu Seyoum, Alemayehu Bekele, Adino Tesfahun Tsegaye, and Simon Birhanu, 'Magnitude and Determinants of Adverse Perinatal Outcomes in Tefera Hailu Memorial Hospital, Sekota Town, Northern Ethiopia', Global Pediatric Health, 8 (2021), $2333794 X 211015524$.

27. Hugara Siddalingappa, MR Nrayana Murthy, Praveen Kulkarni, and NC Ashok, 'Prevalence and Factors Influencing Perinatal Mortality in Rural Mysore, India', Journal of clinical and diagnostic research: JCDR, 7 (2013), 2796.

28. Tadese Ejigu Tafere, Mesganaw Fanthahun Afework, and Alemayehu Worku Yalew, 'Does Antenatal Care Service Quality Influence Essential Newborn Care (Enc) Practices? In Bahir Dar City Administration, North West Ethiopia: A Prospective Follow up Study', Italian journal of pediatrics, 44 (2018), 1-8.

29. Dawit Tiruneh, Nega Assefa, and Bezatu Mengiste, 'Perinatal Mortality and Its Determinants in Sub Saharan African Countries: Systematic Review and Meta-Analysis', Maternal Health, Neonatology and Perinatology, 7 (2021), 1-17.

30. Fentanesh Nibret Tiruneh, Kun-Yang Chuang, and Ying-Chih Chuang, 'Women's Autonomy and Maternal Healthcare Service Utilization in Ethiopia', BMC health services research, 17 (2017), 1-12.

31. Anna A Usynina, Andrej M Grjibovski, Alexandra Krettek, Jon Øyvind Odland, Alexander V Kudryavtsev, and Erik Eik Anda, 'Risk Factors for Perinatal Mortality in Murmansk County, Russia: A Registry-Based Study', Global health action, 10 (2017), 1270536.

32. Joshua P Vogel, Ndema Abu Habib, João Paulo Souza, A Metin Gülmezoglu, Therese Dowswell, Guillermo Carroli, Hassan S Baaqeel, Pisake Lumbiganon, Gilda Piaggio, and Olufemi T Oladapo, 'Antenatal Care Packages with Reduced Visits and Perinatal Mortality: A Secondary Analysis of the Who Antenatal Care Trial', Reproductive health, 10 (2013), 1-7.

33. Haidong Wang, Zulfiqar A Bhutta, Matthew M Coates, Megan Coggeshall, Lalit Dandona, Khassoum Diallo, Elisabeth Barboza Franca, Maya Fraser, Nancy Fullman, and Peter W Gething, 'Global, Regional, National, and Selected Subnational Levels of Stillbirths, Neonatal, Infant, and under-5 Mortality, 1980-2015: A Systematic Analysis for the Global Burden of Disease Study 2015', The Lancet, 388 (2016), 1725-74.

34. Robel Yirgu, Mitike Molla, Lynn Sibley, and Abebe Gebremariam, 'Perinatal Mortality Magnitude, Determinants and Causes in West Gojam: Population-Based Nested Case-Control Study', PloS one, 11 (2016), e0159390.

\section{Tables}

Tables 1 . shows that the perinatal mortality by socio-demographic characteristics of study participants 


\begin{tabular}{|c|c|c|c|}
\hline Variable & Categories & $\begin{array}{l}\text { Frequency } \\
(\%)\end{array}$ & $\begin{array}{l}\text { Perinatal mortality rate (per } \\
1000 \text { ) }\end{array}$ \\
\hline \multirow[t]{5}{*}{ Maternal age (years) } & Less 20 & 151(3.7) & $8(57.14)$ \\
\hline & $20-24$ & $862(20.9)$ & $33(40.69)$ \\
\hline & $25-29$ & $1135(27.5)$ & $54(49.82)$ \\
\hline & $30-34$ & $858(20.8)$ & $26(31.82)$ \\
\hline & $\geq 35$ & $1114(27.0)$ & $61(58.59)$ \\
\hline \multirow[t]{2}{*}{ Residence } & Urban & $760(18.4)$ & $19(25.8)$ \\
\hline & Rural & $3360(81.6)$ & $163(51.6)$ \\
\hline \multirow[t]{3}{*}{ Maternal education status } & No education & $2892(70.2)$ & $134(49.24)$ \\
\hline & Primary & $872(21.2)$ & $36(43.53)$ \\
\hline & $\begin{array}{l}\text { Secondary and } \\
\text { above }\end{array}$ & $356(8.6)$ & $12(34.78)$ \\
\hline \multirow[t]{2}{*}{ Sex of house hold } & Male & $3288(79.8)$ & $153(49.27)$ \\
\hline & Female & $832(20.2)$ & $29(36.80)$ \\
\hline \multirow[t]{3}{*}{ Paternal education status } & No education & $2257(54.8)$ & $111(52.38)$ \\
\hline & Primary & $1041(25.3)$ & $38(38.38)$ \\
\hline & $\begin{array}{l}\text { Secondary and } \\
\text { above }\end{array}$ & $545(13.2)$ & $23(43.80)$ \\
\hline \multirow[t]{2}{*}{ Mother Currently working } & Yes & $936(22.7)$ & $42(47.79)$ \\
\hline & No & $3184(77.3)$ & $140(46.45)$ \\
\hline \multirow[t]{2}{*}{ Family size } & $>4$ & 2954(71.7) & $108(38.37)$ \\
\hline & $\leq 4$ & $1166(28.3)$ & $74(68.64)$ \\
\hline \multirow[t]{3}{*}{ Wealth index } & Rich & $1013(24.6)$ & $20(20.47)$ \\
\hline & Medium & $665(16.1)$ & $22(34.59)$ \\
\hline & Poor & $2442(59.3)$ & $140(61.40)$ \\
\hline \multirow[t]{2}{*}{ Media exposure } & Yes & $1441(35.0)$ & $24(17.30)$ \\
\hline & No & $2679(65.0)$ & $158(63.05)$ \\
\hline \multirow[t]{2}{*}{ Improved water source } & Yes & $2253(54.7)$ & $88(40.93)$ \\
\hline & No & $1867(45.3)$ & $94(53.93)$ \\
\hline Improved toilet facility & Yes & $2281(55.4)$ & $103(47.91)$ \\
\hline
\end{tabular}




\begin{tabular}{|c|c|c|c|c|}
\hline & & No & $1839(44.6)$ & $79(45.32)$ \\
\hline \multirow{2}{*}{$\begin{array}{l}\text { Times to reach } \\
\text { source }\end{array}$} & \multirow{2}{*}{ water } & $<30$ minute & 1686(40.9) & $67(42.00)$ \\
\hline & & $\geq 30$ minutes & $2434(59.1)$ & $115(50.00)$ \\
\hline
\end{tabular}

Tables 2: show that the perinatal mortality by reproductive health characteristics study participants in high mortality regions , Ethiopia,2016. 


\begin{tabular}{|c|c|c|c|}
\hline Variable & Categories & $\begin{array}{l}\text { Frequency } \\
(\%)\end{array}$ & $\begin{array}{l}\text { Perinatal mortality rate } \\
\text { (per 1000) }\end{array}$ \\
\hline \multirow[t]{2}{*}{ Age at first birth } & $<$ 18years & 2002(48.6) & $95(50.29)$ \\
\hline & $\geq 18$ years & $2118(51.4)$ & $87(43.41)$ \\
\hline \multirow[t]{2}{*}{ Place of delivery } & $\begin{array}{l}\text { Health } \\
\text { institution }\end{array}$ & $1853(45.0)$ & $53(29.79)$ \\
\hline & Home & $2267(55.0)$ & $129(61.02)$ \\
\hline \multirow[t]{2}{*}{ Preceding birth interval $(\mathrm{N}=3333)$} & $\geq 2$ years & $2404(72.1)$ & $68(29.42)$ \\
\hline & $<2$ years & $929(27.9)$ & $75(88.86)$ \\
\hline \multirow{2}{*}{$\begin{array}{l}\text { Women participating in making health } \\
\text { care decisions }\end{array}$} & Yes & $3146(76.4)$ & 101(33.73) \\
\hline & No & $974(23.6)$ & $81(91.11)$ \\
\hline \multirow[t]{3}{*}{ Parity } & $1-3$ & $1778(43.2)$ & $70(41.20)$ \\
\hline & $4-6$ & 1435(34.8) & $59(43.51)$ \\
\hline & $\geq 6$ & $907(22.0)$ & $53(63.25)$ \\
\hline \multirow[t]{2}{*}{ Time to breast feeding Initiations } & Within 1 hour & 1933(46.9) & $43(22.76)$ \\
\hline & $>1$ hour & $2187(53.1)$ & 139(69.36) \\
\hline \multirow[t]{2}{*}{ Postnatal care with 2 days } & Yes & $2618(63.5)$ & 107(43.39) \\
\hline & No & 1502(36.5) & $75(52.56)$ \\
\hline \multirow[t]{2}{*}{ Ever had a terminated pregnancy } & No & $3660(88.8)$ & $129(37.34)$ \\
\hline & Yes & $460(11.2)$ & $53(120.72)$ \\
\hline \multirow[t]{3}{*}{ Antenatal care visits } & $\geq 4$ visits & $952(34.6)$ & $23(24.46)$ \\
\hline & $1-3$ visits & $934(33.9)$ & $22(24.10)$ \\
\hline & No at all & $868(31.5)$ & $64(79.11)$ \\
\hline \multirow[t]{3}{*}{ TT vaccination $(\mathrm{N}=2753)$} & Not all & $\begin{array}{l}1241 \\
(45.1)\end{array}$ & $64(54.10)$ \\
\hline & One times & $371(13.5)$ & $7(19.61)$ \\
\hline & $\geq 2+$ & $\begin{array}{l}1141( \\
41.4)\end{array}$ & $37(33.21)$ \\
\hline \multirow[t]{2}{*}{ Distance from Health facilities } & $\begin{array}{l}\text { Not big } \\
\text { problem }\end{array}$ & $2819(68.4)$ & $79(29.32)$ \\
\hline & Big problem & $1301(31.6)$ & 103(85.90) \\
\hline Health insurance & Yes & $3884(94.3)$ & $8(34.33)$ \\
\hline
\end{tabular}


Tables 3:shows the random effect and model comparison for predicting factors of perinatal mortality in high mortality regions, Ethiopia,2016

\begin{tabular}{|lrlll|}
\hline Random effect & \multicolumn{1}{l}{ Null } & Model II & Model III & Model IV \\
\hline Variance & 0.36 & 0.31 & 0.27 & 0.26 \\
\hline Log likelihood & -742.4 & -284.3 & -737.5 & -283.3 \\
\hline Deviance & 1484.8 & 568.6 & 1474.9 & 566.6 \\
\hline ICC & $10 \%$ & $9 \%$ & $8 \%$ & $7 \%$ \\
\hline MOR & 1.77 & 1.69 & 1.63 & 1.62 \\
\hline PCV & Ref & $17 \%$ & $25 \%$ & $28 \%$ \\
\hline
\end{tabular}

Table 4: shows the multivariable multilevel analysis of factors associated with perinatal mortality in high mortality regions, Ethiopia,2016.

1:Reference, OR :Adjusted Odds Ratio, $\mathrm{Cl}$ :Confidence Interval, * $=\mathrm{P} \leq 0.05$ 


\begin{tabular}{|c|c|c|c|c|}
\hline Variable & Null & $\begin{array}{l}\text { Model II } \\
\text { ( AOR }(95 \% \mathrm{Cl})\end{array}$ & $\begin{array}{l}\text { Model III } \\
\text { AOR }(95 \% \mathrm{Cl})\end{array}$ & $\begin{array}{l}\text { Model IV } \\
\text { AOR }(95 \% \mathrm{Cl})\end{array}$ \\
\hline \multirow{3}{*}{$\begin{array}{l}\text { Wealth } \\
\text { index }\end{array}$} & Rich & 1 & & 1 \\
\hline & Medium & $\begin{array}{l}1.45(0.61 \\
3.48)\end{array}$ & & $1.37(0.58,3.32)$ \\
\hline & Poor & $\begin{array}{l}1.06(0.53 \\
2.27)\end{array}$ & & $0.92(0.45,2.00)$ \\
\hline \multirow{2}{*}{$\begin{array}{l}\text { Birth interval } \\
\text { in years }\end{array}$} & $\geq 2$ years & 1 & & 1 \\
\hline & $<2$ years & $3.72(2.28,6.0) *$ & & $3.71(2.27,6.07)^{\star}$ \\
\hline \multirow{2}{*}{$\begin{array}{l}\text { Media } \\
\text { exposure }\end{array}$} & Exposed & 1 & & 1 \\
\hline & $\begin{array}{l}\text { Not } \\
\text { exposed }\end{array}$ & $\begin{array}{l}2.79(1.49 \\
5.60)^{\star}\end{array}$ & & $2.78(1.48,5.59)^{*}$ \\
\hline \multirow{3}{*}{$\begin{array}{l}\text { Antenatal } \\
\text { care visits }\end{array}$} & $\geq 4$ visits & 1 & & 1 \\
\hline & $1-3$ visits & $\begin{array}{l}0.82(0.39 \\
1.73)\end{array}$ & & $0.79(0.37,1.69)$ \\
\hline & No at all & $\begin{array}{l}2.51( \\
1.18,5.54)^{*}\end{array}$ & & $2.43(1.15,5.38)^{\star}$ \\
\hline \multirow{3}{*}{$\begin{array}{l}\text { TT- } \\
\text { vaccination }\end{array}$} & Not all & 1 & & 1 \\
\hline & 1 & $0.59(0.22,1.38)$ & & $0.56(0.21,1.33)$ \\
\hline & $\geq 2+$ & $\begin{array}{l}0.68(0.36 \\
1.29)\end{array}$ & & $0.68(0.36,1.29)$ \\
\hline \multirow[t]{2}{*}{$\begin{array}{l}\text { Place of } \\
\text { delivery }\end{array}$} & $\begin{array}{l}\text { Health } \\
\text { Institution }\end{array}$ & 1 & & 1 \\
\hline & Home & $\begin{array}{l}1.23(0.71 \\
2.16)\end{array}$ & & $1.25(0.72,2.22)$ \\
\hline \multirow{2}{*}{$\begin{array}{l}\text { Time to } \\
\text { breast } \\
\text { feeding } \\
\text { initiation }\end{array}$} & $\begin{array}{l}\text { With } \\
\text { 1hour }\end{array}$ & 1 & & 1 \\
\hline & $>1$ hour & $\begin{array}{l}3.95(2.50 \\
6.40)\end{array}$ & & $4.01(2.49,6.51)^{\star}$ \\
\hline \multirow{2}{*}{$\begin{array}{l}\text { Post natal } \\
\text { follow up } \\
\text { with in } 2 \text { day }\end{array}$} & Yes & 1 & & 1 \\
\hline & No & $\begin{array}{l}0.93(0.53 \\
1.66)\end{array}$ & & $0.93(0.53,1.67)$ \\
\hline \multirow[t]{2}{*}{ Parity } & $1-3$ & 1 & & 1 \\
\hline & $4-6$ & $1.53(0.78,3.03)$ & & $1.54(0.79,3.08)$ \\
\hline
\end{tabular}




\begin{tabular}{|c|c|c|c|c|}
\hline & $\geq 6$ & $2.55(1.24,5.37)^{\star}$ & & $2.48(1.21,5.22)^{\star}$ \\
\hline \multirow{2}{*}{$\begin{array}{l}\text { Ever had } \\
\text { terminated } \\
\text { pregnancy }\end{array}$} & No & 1 & & 1 \\
\hline & Yes & $4.68(2.76,7.86)^{\star}$ & & $4.68(2.75,7.86) *$ \\
\hline \multirow[t]{2}{*}{ Family size } & $>4$ & 1 & & 1 \\
\hline & $\leq 4$ & $4.06(2.15,7.69)^{\star}$ & & $4.12(2.19,7.79) *$ \\
\hline \multirow{2}{*}{$\begin{array}{l}\text { Women } \\
\text { participating } \\
\text { in making } \\
\text { health care } \\
\text { decisions }\end{array}$} & Yes & 1 & & \\
\hline & No & $1.97(1.20,3 \cdot 21)^{\star}$ & & $1.96(1.19,3.20) *$ \\
\hline \multirow{2}{*}{$\begin{array}{l}\text { Distance } \\
\text { from health } \\
\text { facility }\end{array}$} & $\begin{array}{l}\text { Not big } \\
\text { problem }\end{array}$ & & 1 & 1 \\
\hline & $\begin{array}{l}\text { Big } \\
\text { problem }\end{array}$ & & $2.80(2.06,3.82) *$ & $1.99(1.24,3.22)^{*}$ \\
\hline \multirow[t]{2}{*}{ Residence } & Urban & & 1 & 1 \\
\hline & Rural & & $\begin{array}{l}1.53(0.95 \\
2.61)\end{array}$ & $0.93(0.44,2.19)$ \\
\hline \multirow{2}{*}{$\begin{array}{l}\text { Time to } \\
\text { reach to } \\
\text { water } \\
\text { source }\end{array}$} & $\begin{array}{l}<30 \\
\text { minute }\end{array}$ & & 1 & 1 \\
\hline & $\begin{array}{l}\geq 30 \\
\text { minute }\end{array}$ & & $1.32(0.97,1.80)$ & $1.38(0.85,2.30)$ \\
\hline
\end{tabular}

